\title{
PENGUNDERAITAN DALAM PRODUK TAKAFUL KELUARGA DARI PERSPEKTIF SYARIAH
}

\section{Family Takaful Product Underwriting From Shariah Perspective}

\author{
Aisyah Mustafa ${ }^{1}$ \\ Asmak Ab Rahman ${ }^{2}$
}

\begin{abstract}
In the insurance operations, underwriting procesess are important to determine the premium rate that would be applicable to individuals who wanted to be insured. These processes involves the assessment and examination of the individual in order to fix the rates and risk classes. Takaful operators have known to have a similar practices with the insurance companies in the underwriting processes. Thus, all the issues facing by the insurance companies which are related to the underwriting processes may also occurs in the takaful industry. For example, in the conventional insurance, including gender and family background in the underwriting issues are seen as unfair by the insurance experts. Rigid underwriting processes can also restricted the participations into takaful plans. Strict evaluation in
\end{abstract}

\footnotetext{
1 Master Candidate, Department of Shariah and Economics, Academy of Islamic Studies, University of Malaya, Kuala Lumpur, aisyah.mustafa@gmail.com

2 Senior Lecturer, Department of Shariah and Economics, Academy of Islamic Studies, University of Malaya, Kuala Lumpur, asmak@um.edu.my
} 
the application will cause the unhealthy applicants to be rejected. There is also a view that stated that the underwriting practices are against the concept of mutual help in takaful. Hence, to ascertain the importance of underwriting processes in takaful, literature research, encompassing books, papers and journals, were used to obtain information. A field study was also conducted by using the interview method. Interviews are conducted amongst the underwriters and a number of Shariah advisors from few takaful operators. The main focus of this study is to gain the Shariah's insight on the underwriting practices, primarily to justify whether it is in accordance to the shariah principles. This analytical findings of this case study has concluded that the underwriting processes that currently being practiced in the takaful industry is in accordance with the Islamic principles.

Keywords: underwriting process, takaful, Islamic law, Shariah

\section{PENDAHULUAN}

Islam sentiasa menganjurkan umatnya agar bersiap sedia dalam menghadapi sebarang kemungkinan berlakunya musibah di dalam kehidupan. Tanpa persediaan awal, manusia mungkin akan berhadapan dengan risiko yang lebih berat. Risiko pula diertikan sebagai kemungkinan akan berlaku kerugian. Dalam erti kata lain, kemungkinan sesuatu yang diharapkan tidak berlaku tetapi terjadi pula sesuatu yang membawa kepada kerugian. ${ }^{3}$ Kemalangan, kematian, bencana alam adalah antara jenis-jenis risiko yang mungkin berlaku di dalam kehidupan. Setiap individu perlu membuat persiapan untuk berdepan dengan kemungkinan terjadinya risiko-risiko sebegini agar kesannya dapat diminimumkan dan tidak memberi kesan negatif yang mendalam ke atas diri individu serta orang-orang tersayang.

Takaful merupakan satu usaha kerjasama, lindung-melindungi dan tolongmenolong di antara anggota masyarakat yang menginginkan perlindungan dalam menghadapi kemungkinan malapetaka atau bencana. Islam juga turut menganjurkan umatnya agar itu lebih peka dalam memastikan nyawa dan harta bendanya terjamin dan terpelihara. Sabda Rasulullah SAW:

$3 \quad$ James L. Athearn, Risk and Insurance (New York: West Publishing Co., 1997), 17; Vaughan, E. J, Risk Management (New York: John Wiley \& Son, Inc., 1997), 8. 


$$
\text { المؤمن من أمنه الناس على دمائهم و أمو الهم }
$$

"Sesungguhnya seseorang yang beriman ialah sesiapa yang memberi keamanan (keselamatan dan perlindungan) terhadap harta dan jiwa raga manusia." 4

Takaful secara khususnya dikendalikan oleh Syarikat Takaful sebagai pengusaha melalui skim dan pelan takaful yang disusun dengan berlandaskan hukum-hukum syariat. Usaha bagi mewujudkan kerjasama dan lindungmelindungi ini selari dengan tuntutan Islam sebagaimana yang dijelaskan di dalam al-Quran:

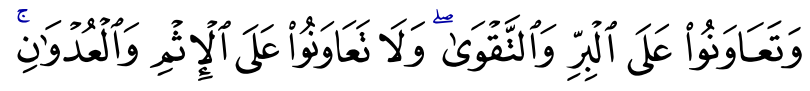

"Dan hendaklah kamu tolong-menolong dalam melakukan kebaikan dan taqwa dan janganlah kamu tolong-menolong dalam melakukan dosa dan perseteruan."

(Surah al-Mā’idah, 5: 2)

Secara umumnya, bisnes takaful ini dapat dibahagikan kepada dua jenis, iaitu takaful keluarga dan takaful am. ${ }^{5}$ Takaful keluarga menawarkan perlindungan jangka panjang yang kebiasaannya dalam tempoh lebih daripada satu tahun. Ia menyediakan manfaat kewangan sekiranya individu mengalami sebarang musibah atau mendapat keuntungan dalam pelaburan yang berpotensi terutamanya dalam produk yang berasaskan pelaburan. Dalam takaful keluarga, risiko yang dilindungi termasuklah kematian awal, penyakit, dan hilang upaya kekal. ${ }^{6}$ Terdapat beberapa jenis produk yang boleh dipohon oleh individu, antaranya produk yang menawarkan perlindungan selepas bersara, perubatan, pendidikan, pelaburan dan sebagainya.

Takaful am pula adalah kontrak jaminan bersama. $^{7}$ Kebiasaannya ia menawarkan perlindungan jangka pendek yang melindungi dalam tempoh satu tahun ataupun kurang. Namun begitu ia boleh juga melindungi lebih daripada tempoh tersebut. Kontrak takaful am dibentuk untuk memberi perlindungan

4 Muhammad bin Yazid al-Qazwīn̄i, Sunan Ibn Majah, bāb hurmatu dam al-mu'min wa al-māluhu, no. hadith 3934 (Arab Saudi: Dār Iḥyā’ al-Kutub al-'Arabiyyah), 1298.

5 INCIEF, Takaful:Reality and Challenge (Petaling Jaya: Pearson Malaysia Sdn. Bhd., 2012), 244.

6 INCIEF, Takaful:Reality and Challenges, 245.

7 INCIEF, Takaful:Reality and Challenges, 377. 
sekiranya berlaku sebarang kerugian, kerosakan yang besar atau kecederaan disebabkan berlakunya sesuatu peril. ${ }^{8}$

Kemunculan sistem takaful sebagai instrumen perlindungan merupakan alternatif terbaik kepada umat Islam untuk mengelakkan penggunaan prinsipprinsip yang dilarang dalam Islam terutamanya bagi pengendalian risiko sesuatu aktiviti. ${ }^{9}$ Takaful adalah antara institusi yang mengamalkan prinsipprinsip Syariah dalam pelaksanaannya dan setiap operasi yang dijalankan perlulah berlandaskan Syariah yang dipantau oleh Jawatankuasa Pengawasan Syariah. Selain daripada itu, takaful juga dapat menggalakkan manusia supaya tolong-menolong dan bekerjasama dalam membantu manusia yang ditimpa musibah seiring dengan konsep ta 'āwun yang diamalkan dalam takaful.

Walaupun prinsip asas takaful adalah untuk saling jamin menjamin antara satu sama lain, namun dalam pelaksanaannya individu yang ingin menyertai takaful perlu melalui proses pemilihan dan penilaian sebelum diterima menyertai takaful. Ini kerana, pengunderait akan menilai dan memilih mereka yang benar-benar layak sahaja untuk menyertai takaful. Proses ini adalah proses yang diadaptasi daripada rangka kerja insurans konvensional. Pemilihan ini akan dilakukan dengan menilai individu dengan merujuk kepada beberapa kriteria bagi menentukan status kesihatan pemohon, seterusnya ia akan menentukan kelas risiko pemohon. Contohnya bagi produk kad kesihatan, pengunderait akan meminta pemohon untuk mengisi borang permohonan dengan mengemukakan fakta-fakta yang diperlukan oleh syarikat takaful untuk proses pemilihan tersebut. Fakta yang dikehendaki adalah berkaitan dengan soalan-soalan yang menjurus kepada tahap kesihatan dan perihal diri pemohon. Seterusnya selepas diri pemohon dinilai, pengunderait akan mengeluarkan keputusan pengunderaitan dengan mengklasifikasikan pemohon sama ada di bawah kategori standard, sub-standard atau decline.

Standard merujuk kepada permohonan yang diterima oleh syarikat takaful mengikut apa yang telah dipohon oleh individu tersebut. Mereka juga akan dikenakan bayaran sumbangan yang biasa seperti yang dipersetujui dalam pelan yang dipohon. Berlainan pula bagi kes sub-standard, kebiasaaannya merujuk kepada pemohon yang mempunyai risiko yang tinggi seperti, mempunyai gaya hidup yang tidak sihat contohnya merokok, menghidap beberapa jenis penyakit, bekerja dalam suasana yang berisiko, dan sebagainya. Oleh itu, mereka ini akan dikenakan caj tambahan, atau pengecualian terhadap perlindungan bagi penyakit-penyakit tertentu. Ini bermakna walaupun pemohon dikenakan

$8 \quad$ INCIEF, Takaful:Reality and Challenges, 377.

9 Mohd Fauzi Abu \& Kamaruzaman Nordin, 'Perkembangan dan Prospek Industri Takaful Global,' dalam Sistem Takaful di Malaysia Isu-isu Kontemporari, ed. Asmak Ab. Rahman et al. (Kuala Lumpur: Universiti Malaya, 2008), 83-97. 
bayaran tambahan berbanding kadar normal yang dikenakan kepada peserta takaful yang normal, namun pemohon ini tidak akan mendapat manfaat kewangan sekiranya musibah berlaku disebabkan oleh penyakit tertentu yang dihidapinya sebelum menyertai takaful. Sekiranya pemohon mempunyai penyakit yang teruk, mempunyai pekerjaan yang bahaya, atau mempunyai sejarah keluarga yang menghadapi penyakit-penyakit kronik, pengunderait akan menolak permohonan tersebut. Penolakan itu dilakukan kerana bayaran tambahan yang dikenakan tidak mampu menampung risiko yang dibawa oleh pemohon tersebut.

Ini jelas menunjukkan kelayakan seseorang dalam menyertai takaful bergantung kepada proses pengunderaitan yang diamalkan oleh syarikat takaful. Oleh kerana itu, terdapat persoalan mengapa pengunderaitan perlu dilakukan sedangkan takaful itu berkonsepkan ta'āwun yang mana penyertaan setiap individu dalam takaful itu dapat membantu pihak-pihak yang memerlukan dengan menjadikan tabarru ' itu sebagai asas kepada sistem takaful.

Roslinah Daud ${ }^{10}$ berpendapat proses pengunderaitan yang ketat boleh menyekat penyertaan orang ramai untuk menyertai takaful. Penilaian yang rapi dilakukan ke atas setiap permohonan untuk memilih peserta yang benarbenar sihat sahaja akan menyebabkan permohonan seseorang yang kurang sihat tetapi ingin menyertai takaful ditolak. Menurut beliau, pemeriksaan kesihatan yang sangat ketat dijalankan untuk menentukan status kesihatan seseorang tidak melambangkan konsep ta ' $\bar{a} w u n$ dan kerjasama dalam takaful. ${ }^{11}$ Sedangkan konsep bantu-membantu dan bekerjasama ini merupakan amalan murni yang dituntut dalam Islam. Oleh kerana asas takaful itu adalah tabarru ; proses pengunderaitan ini dilihat seolah-olah tidak selaras dengan konsep yang digunakan.

Dari perspektif pengamal insurans konvensional pula, isu ini turut juga dibincangkan oleh Wouter P. J, ${ }^{12}$ Joseph Heath ${ }^{13}$ dan Daniel E. Palmer ${ }^{14}$ yang mana mereka melihat proses pengunderaitan dalam insurans hayat yang

10 Roslinah Daud, 'Underwriting Family Schemes,' ICMIF Takaful (2009). Lihat http://www.takaful.coop/index.php?option=com_content\&view $=$ article\&id $=73 \&$ Itemid=145, diakses pada 10 Mei 2014.

11 Roslinah Daud, 'Underwriting Family Schemes,' 4.

12 Wouter P. J., 'Insurance Risk Classification in The EC: Regulatory Outbook,' Oxford Journal of Legal Studies 14 (1994): 449-467.

13 Joseph Heath, 'Reasonable Restrictions on Underwriting,' Research in Ethical Issues in Organizations, vol. 7 (2007): 127-159.

14 Daniel E. Palmer, 'Risk Assesment and Fairness: An Ethical Analysis,' in Insurance Ethics for a More Ethical World (Elsevier Ltd., 2007).113-126. 
mengambil kira jantina dan latar belakang keluarga sebagai salah satu faktor dalam pengunderaitan adalah tidak adil. Mereka berpandangan insurans adalah suatu manfaat sosial dan ianya tidak patut menolak permohonan indivdu berdasarkan keadaan yang berada di luar kawalan mereka.

Artikel ini akan membincangkan kedudukan dan proses pengunderaitan dalam produk takaful keluarga dari perspektif Syariah. Apakah pandangan Syariah tentang proses pengunderaitan? Adakah ianya bertepatan dengan Syariah atau ia tidak bertepatan dengan Syariah? Pengkaji merujuk kepada dokumen-dokumen berkaitan isu-isu yang dibangkitkan meliputi buku-buku, artikel, jurnal dan kertas kerja berkaitan dengan takaful. Analisa pula dibuat untuk melihat pandangan Syarak terhadap kaedah pengunderaitan dengan merujuk kepada dalil-dalil Syarak yang merupakan sumber utama dalam perundangan Islam.

Pada asasnya pengkaji mendapati bahawa tiada perbincangan yang khusus berkaitan dengan amalan pengunderaitan ini dalam kalangan fuqaha'. Tetapi pengkaji mengaitkannya dengan kaedah fiqh iaitu الأصل في الأشياء الإباحة yang bermaksud asal sesuatu perkara itu adalah harus. ${ }^{15}$

\section{KONSEP PENGUNDERAITAN DALAM INSURANS DAN TAKAFUL}

Pengunderaitan merupakan proses pemilihan dan pengelasan risiko yang dilakukan oleh syarikat insurans ke atas pemohonan insurans oleh individu untuk melindungi harta dan liabiliti. ${ }^{16}$ Ia juga merupakan salah satu proses bagi menentukan kadar sumbangan yang bakal dikenakan kepada individu. Proses ini melibatkan penaksiran dan pemeriksaan terhadap individu bagi menetapkan kadar dan kelas risiko. ${ }^{17}$ Secara ringkasnya, ia adalah satu proses pemilihan risiko yang mana ia akan menentukan sama ada sesuatu risiko itu akan diterima atau ditolak oleh syarikat. ${ }^{18}$ Pengunderaitan juga merupakan proses yang amat penting dalam syarikat untuk mengelak daripada berlakunya

5 Jalāl al-Dīn 'Abd al-Rahmān al-Ṣuyūtị, al-Ashbah wa al-Naẓā'ir fì Qawā 'id wa Furu' Fiqh al-Syāfi 'iyah (Beirūt: Dār al-Kutb al-'Ilmiyah, 2007), 101.

16 Hendon Redzuan et al., Prinsip Pengurusan Risiko dan Insurans (Petaling Jaya: Person Malaysia Sdn. Bhd., 2006), 180.

17 Htay et al., 'Shariah Scholars' Viewpoint on The Practice of Underwriting and Rating for Individual Participants in Family Takaful,' (International Islamic Banking, Finance and Investment Conference, 19-20 Disember 2011), 4.

18 Ahmad Mazlan Zulkifli et al., Asas Amalan Takaful: Pengunderaitan Takaful Perubatan dan Kesihatan (Kuala Lumpur: IBFIM, 2012), 217. 
anti-pemilihan (adverse selection) ${ }^{19}$ iaitu individu yang berisiko tinggi lebih cenderung untuk membeli insurans daripada individu yang berisiko rendah. ${ }^{20}$ Masalah anti-pemilihan ini timbul apabila individu yang berisiko tinggi berjaya mendapat perlindungan dengan membayar kadar sumbangan yang rendah atau pada kadar biasa. Oleh itu, syarikat perlu mengelak daripada berlakunya antipemilihan ini kerana ia akan melibatkan bilangan tuntutan yang tinggi dan menyebabkan kedudukan kewangan syarikat akan terjejas. ${ }^{21}$

Setiap permohonan yang dilakukan oleh individu untuk membeli insurans akan dinilai tahap risiko yang dibawa oleh pemohon terlebih dahulu. Syarikat perlu mengenalpasti keadaan setiap individu supaya berada dalam keadaan baik. Oleh itu, maklumat seperti umur, jantina, tahap kesihatan, latar belakang keluarga, jenis pekerjaan, hobi dan sebagainya merupakan antara faktor-faktor pengunderaitan yang digunakan untuk menilai risiko pemohon.

Faktor umur pula adalah antara faktor utama yang menentukan kadar premium individu. Begitu juga dengan faktor jantina, yang mana lelaki dan perempuan akan dikenakan bayaran yang berlainan disebabkan lelaki dan perempuan mempunyai tahap kemortalan (kematian) dan kemorbidan (penyakit) yang berbeza. ${ }^{22}$

Selain daripada itu, syarikat insurans juga lazimnya akan melihat keadaan fizikal individu iaitu berat dan tinggi. Ini kerana berdasarkan pengalaman yang lepas, berat badan berlebihan cenderung menghadapi kematian yang awal. ${ }^{23}$ Pemohon juga akan dinilai keadaan dirinya semasa membuat permohonon takaful untuk mendapatkan maklumat yang tepat mengenai tahap kesihatan pemohon. Manakala, sejarah kesihatan keluarga pemohon turut diambil kira kerana ia turut mempengaruhi tahap kesihatan individu pada masa akan datang. ${ }^{24}$

Syarikat insurans lazimnya akan memilih pemohon yang kurang berisiko. Oleh itu, tabiat individu seperti merokok, pengambilan dadah dan alkohol turut dijadikan sebagai faktor pengunderaitan. ${ }^{25}$ Begitu juga mereka yang

19 Vaughan E. J \& Vaughan T. M, Essential of Insurance: A Risk Management Perspective (USA: John Wiley \& Sons, INC., 1995), 112.

20 Ahmad Mazlan et al., Asas Amalan Takaful, 224.

21 Hendon Redzuan et al., Prinsip Pengurusan Risiko, 59.

22 Ahmad Mazlan et al., Asas Amalan Takaful, 229.

23 Eric A. Wiening et al., Personal Insurance (America: American Institute for Chartered Property Casualty Underwriters/Insurance Institute of America, 2002), 23.

24 Ahmad Mazlan et al., Asas Amalan Takaful, 226.

25 Eric A. Wiening et al., Personal Insurance, 23. 
mempunyai hobi yang merbahaya seperti mendaki, menyelam, lumba kereta dan sebagainya. Aktiviti seperti ini terdedah kepada risiko kemalangan dan kematian yang tinggi. Faktor-faktor tersebut turut dinilai syarikat untuk memastikan tahap risiko yang dibawa oleh pemohon mampu untuk ditanggung oleh syarikat.

Manakala bagi mereka yang mempunyai pekerjaan yang merbahaya, kemungkinan tuntutan perbelanjaan perubatan adalah tinggi ${ }^{26}$ Oleh itu, mereka akan dikenakan premium yang tinggi.

Setelah pengunderait menilai borang cadangan yang telah diisi oleh pemohon, keputusan pengunderaitan akan ditentukan. Pengunderait akan menentukan keputusan pengunderaitan sama ada berskala standard iaitu bayaran sumbangan yang dikenakan adalah seperti yang telah dipersetujui mengikut apa yang dipohon, sub-standard pula sekiranya pemohon mempunyai risiko yang tinggi dan akan dikenakan bayaran tambahan (loading) atau penangguhan permohonan dan pengecualian terhadap beberapa perlindungan yang ditawarkan. Manakala, penolakan permohonan akan dilakukan sekiranya tahap kesihatan dan sejarah keluarga, hobi dan pekerjaan berada dalam tahap bahaya atau berisiko tinggi.

Proses pengunderaitan yang diamalkan ini sangat penting dalam menentukan kelangsungan sesebuah syarikat insurans. Keputusan atau hasil pengunderaitan yang baik adalah perlu untuk pertumbuhan yang menguntungkan, bahkan ia juga boleh mengekalkan kebolehtahanan syarikat. ${ }^{27}$

Syarikat takaful juga mempunyai amalan yang sama dengan syarikat insurans dalam proses pengunderaitan dan pengkelasan risiko. ${ }^{28}$ Semua faktor seperti umur, jantina, latar belakang keluarga, pekerjaan, hobi dan sebagainya turut dijadikan ukuran dalam penerimaan permohonan pemohon. Jika amalan pengunderaitan yang diamalkan di syarikat takaful adalah sama seperti syarikat insurans, ini bermakna segala isu yang dihadapi oleh syarikat insurans yang berkaitan dengan proses pengunderaitan berkemungkinan juga berlaku dalam syarikat takaful. ${ }^{29}$ Perkara ini dilihat boleh menimbulkan keraguan dan sewajarnya dikaji terutamanya yang melibatkan amalan dan proses

\footnotetext{
26 Ahmad Mazlan et al., Asas Amalan Takaful, 222.

27 Bernard L. Webb, Connor M. Harrison \& James J. Markham, Insurance Operation, ed. ke-2 (Malvern: American Institute for Chartered Property Casualty Underwriter, 1997), 119.

28 Tobias Frenz et al., Takaful and Retakaful: Advanced Principles \& Practice. (Kuala Lumpur: IBFIM, 2010), 67.

29 Htay et al., Shariah Scholars', 1-17.
} 
pengunderaitan yang diadaptasi daripada syarikat insurans konvensional bagi memastikan sama ada ianya menepati hukum Syarak ataupun tidak.

\section{PERBEZAAN KEDUDUKAN DANA TABARRU ${ }^{`}$ DALAM TAKAFUL DENGAN DANA INSURANS}

Insurans konvensional adalah sebuah kontrak yang melibatkan dua pihak iaitu syarikat insurans dan pemegang polisi. Syarikat insurans merupakan pihak yang akan memberi pampasan dalam bentuk kewangan sekiranya berlaku sesuatu musibah seperti kebakaran, kemalangan, kecurian dan sebagainya. Manakala, pemegang polisi pula merupakan pihak yang membayar sejumlah wang untuk mendapatkan perlindungan daripada syarikat insurans dalam bentuk kewangan sekiranya berlaku sesuatu peristiwa yang tidak diingini. Ia adalah kontrak jual beli iaitu pemegang polisi berjanji akan membayar sejumlah premium untuk mendapat jaminan perlindungan kewangan dalam bentuk pampasan daripada syarikat insurans. ${ }^{30}$

Takaful pula merupakan kontrak saling jamin-menjamin dan lindungmelindungi. Konsep ini mengandungi prinsip bekerjasama, tolong-menolong dan bertanggunggjawab. ${ }^{31}$ Sehubungan dengan itu, setiap peserta yang menyertai takaful bersetuju untuk bantu-membantu sesama peserta sekiranya terdapat di antara mereka yang ditimpa bencana atau malapetaka. Ini bermakna di dalam kontrak takaful, tiada unsur jual beli. Kontrak dalam takaful ini adalah berpaksikan elemen kerjasama yang tulen dan menggunakan pendekatan tabungan bersama menerusi konsep tabarru : ${ }^{32}$

Pembentukan dana yang berkonsepkan tabarru' dalam operasi takaful ini sangat penting kerana dana ini yang akan digunakan untuk menyalurkan bantuan kewangan atau pampasan kepada peserta yang ditimpa musibah. ${ }^{33}$ Dana tabarru' ini terbentuk melalui sumbangan daripada Dana Risiko atau Akaun Khas Peserta. Wang yang terkumpul daripada tabung Dana Risiko ini hanya boleh digunakan untuk pihak yang terlibat dalam akad takaful sahaja.

30 Vaughan, E. \& Vaughan T., Fundamentals of Risk and Insurance (New York: John Wiley and Sons, 2003), 159; Trieschmann James S dan Gustavson Sandra G., Risk Management \& Insurance (Ohio: South-Western College Publishing, 1998), 123.

31 Nik Ramlah Nik Mahmood, 'Takaful: The Islamic System of Mutual InsuranceThe Malaysian Insurasce', Arab Law Quarterly (Februari 1991), 286-287.

32 Muhammad Hisyam Mohamad, 'Perbandingan Kontrak Takaful dan Insurans', dalam Sistem Takaful di Malaysia, ed. Asmak Ab. Rahman et al. (Kuala Lumpur: Penerbit Universiti Malaya, 2008), 29.

33 Muhammad Hisyam Mohamad, 'Perbandingan Kontrak Takaful dan Insurans', 29. 
Pihak yang tidak terlibat dalam akad tersebut tidak berhak untuk mendapat manfaat daripada wang tersebut.

Melalui konsep penyertaan dan tabarru' ini, syarikat takaful bertindak sebagai pemegang amanah yang akan menguruskan semua dana takaful dan diagihkan kepada peserta yang memerlukan sahaja. Sebagai pemegang amanah juga, syarikat takaful perlu memastikan dana syarikat sentiasa berada dalam keadaan yang baik bagi melakukan bayaran tuntutan sekiranya terdapat peserta yang ditimpa musibah.

Dalam kontrak insurans pula, syarikat insurans mempunyai kuasa penuh ke atas premium yang dibayar dan wang yang terkumpul adalah merupakan milik syarikat. Ia hanya bertanggungjawab untuk membayar pampasan kepada pemegang polisi jika berlaku sesuatu yang tidak diduga. ${ }^{34}$

Ini kerana, kontrak insurans tidak berasaskan penyertaan. Ia adalah suatu kontrak jual beli yang mana wujud transaksi individu yang membeli polisi berharap untuk mendapatkan pampasan oleh syarikat insurans jika terjadi malapetaka ke atas mereka. Bayaran pemium yang terkumpul dalam dana insurans akan digunakan untuk membayar tuntutan, perbelanjaan pengurusan, komisyen dan sebagainya. Sekiranya terdapat baki daripada dana tersebut ia merupakan keuntungan syarikat. ${ }^{35}$

Oleh yang demikian, dapat dijelaskan terdapat perbezaan antara dana di syarikat insurans dan takaful. Dana dalam syarikat takaful perlu lebih dilindungi kerana ia bukan hanya milik syarikat tetapi juga milik bersama setiap peserta. Ini adalah berlandaskan konsep tabarru' yang diterapkan dalam operasi takaful. Maka, menjadi tanggungjawab syarikat takaful untuk menguruskan dana syarikat dengan lebih teliti agar dapat mengekalkan kebolehtahanan dan kelangsungan syarikat pada masa akan datang. Sebaliknya, dalam insurans konvensional, tiada sebarang perkongsian dalam apa jua urusan dan syarikat berhak mengambil lebihan dana sekiranya terdapat lebihan dalam bayaran tuntutan yang dilakukan.

\section{ANALISIS SYARIAH DALAM PENGUNDERAITAN PRODUK TAKAFUL KELUARGA}

Operasi dalam perniagaan takaful dalam kerangka moden pada masa kini dilihat sebagai satu konsep muamalat yang baru berbanding dengan yang diamalkan pada zaman Rasulullah. Secara umumnya, Syariah sama sekali tidak

34 Muhammad Hisyam Mohamad, 'Perbandingan Kontrak Takaful dan Insurans,' 23.

35 Muhammad Hisyam Mohamad, 'Perbandingan Kontrak Takaful dan Insurans,' 31. 
menyekat dalam memenuhi kehendak individu ketika melakukan muamalat. Ini menunjukkan bahawa hukum Islam itu bersifat fleksibel mengikut keadaan, tempat dan masa. Secara umumnya, tiada perbincangan yang khusus di dalam al-Quran dan hadis berkaitan dengan amalan pengunderaitan yang diamalkan dalam industri takaful dan tiada dalil yang mengharamkan dan menghalang amalan pengunderaitan ini dilakukan. Melihat kepada sistem takaful yang berkonsepkan tabarru', maka dirumuskan bahawa amalan pengunderaitan yang diamalkan tidak bercanggah dari sudut fiqh kerana ia merupakan suatu keputusan perniagaan yang diguna pakai bagi mengurangkan risiko yang ditanggung oleh dana tabarru :

Malah jika dilihat kepada perkara berkaitan dengan muamalat secara umumnya, Islam menerima kontrak-kontrak berkaitan keewangan yang lazim diamalkan oleh masyarakat Arab sebelum kedatangan Islam seperti mud̄ārabah, ijārah, jual beli dan sebagainya. Pengiktirafan kepada kontrakkontrak kewangan yang lazim diamalkan dan diperkemaskan dengan peraturanperaturan tertentu membolehkan masyarakat Islam dapat melaksanakan hal berkaitan kewangan mereka dengan berkesan. Larangan pula hanya melibatkan beberapa larangan sahaja iaitu pengharaman riba, gharar dan maysīr. Peraturan berkaitan pengurusan hal ehwal kewangan dan kehartaan ini turut dipandu oleh beberapa panduan dan galakan seperti larangan penyorokan barang, bersikap jujur dan amanah dalam jual beli dan sebagainya. Secara ringkasnya peraturanperaturan tersebut adalah untuk memenuhi hajah manusia untuk bermuamalat dan penjagaan hak bagi pihak-pihak yang berkontrak. ${ }^{36}$ Oleh itu dalam operasi takaful yang diadaptasi dari operasi insurans yang menjadikan pengunderaitan sebagai satu proses pemilihan peserta takaful dilihat sebagai satu proses untuk menjaga hak bagi pihak-pihak yang terlibat dalam perniagaan takaful ini.

Penggunaan faktor-faktor pengunderaitan dalam produk takaful ini dapat dikaitkan dengan kaedah fiqh الأصل في الأشياء الإباحة حتى يدل الدليل على التحريم yang bermaksud asal sesuatu perkara itu adalah harus sehingga ada dalil yang mengharamkannya. ${ }^{37}$ Ia merujuk kepada keharusan yang diterima pakai apabila perkara tersebut tidak berlawanan dengan nas Syarak. Maka, amalan ini boleh dilakukan selagi tidak bercanggah dengan syariat serta selagi mana

36 Yūsuf al-Qaraḍāwī, Fì Fiqh Awlāwiyyat: Dirāsat Jadīdah Daw'al-Qur'ān wa alSunnah (Qāhirah: Maktabah Wahbah, 1999), 125; Muhammad 'Uthmān Shubāyr, al-Mu 'āmalāt al-Māliyyah al-Mu 'āṣirah (Oman: Dār al-Nafā' is, 2007), 19; Basri Ibrahim, Urusan Kewangan Semasa Menurut Perspektif Islam (Kuala Lumpur: al-Hidayah, 2005), 2.

37 Jalāl al-Dīn 'Abd al-Rahmān al-Șuyūṭị, al-Ashbah wa al-Naẓā'ir fì Qawā 'id wa Furu' Fiqh al-Shāfi 'iyah, 101. 
ia tidak melibatkan aktiviti muamalat yang diharamkan. Jadi adakah proses pengunderaitan berlawanan dengan Syarak. Berdasarkan panduan Islam yang melarang urusniaga yang mengandungi riba, gharar dan maysīr dilihat bahawa proses pengunderaitan tidak terlibat dengan elemen riba, gharar dan maysīr.

Selain itu, kaedah fiqh العادة محكمة ${ }^{38}$ adalah garis panduan Syariah yang digunapakai di dalam amalan di syarikat takaful. Proses pengunderaitan yang diamalkan dalam takaful ini merupakan 'urf dalam perniagaan insurans. 'Urf dalam industri takaful yang digunapakai di dalam proses pengunderaitan dilihat berkesan dalam menilai risiko yang dibawa oleh pemohon. Ia merupakan suatu pendekatan yang diambil di dalam industri takaful selagi ianya tidak bertentangan dengan nas Syarak. Dalam hal ini, walaupun tiada hukum pada asalnya mengenai pendekatan pengunderaitan yang diamalkan, namun selagi mana 'urf yang digunakan dilihat tidak bercanggah dengan hukum Syarak maka ianya boleh diterima.

Proses pengunderaitan yang diamalkan ini juga adalah untuk mengelakkan daripada berlakunya sebarang bentuk kemudaratan. Syarikat akan memastikan peserta dan pemegang saham tidak terdedah kepada kemudaratan, ini sesuai dengan kaedah iaitu الضرر يز ال yang bermaksud kemudaratan harus dihilangkan ${ }^{39}$ dan لاضرر ولاضرار yang bermaksud tidak mudarat dan tidak memudaratkan. ${ }^{40}$

Malahan, dalam situasi tertentu seperti pemohon mempunyai masalah kesihatan yang serius, pengunderait akan mengenakan lebihan caj terhadap pemohon. Keputusan pengunderait untuk mengenakan kadar tabarru ' yang tinggi kepada pemohon yang berisiko tinggi selaras dengan kaedah fiqh iaitu Penyertaan pemohon yang berisiko tinggi akan menjejaskan kestabilan dana syarikat. Maka kemudaratan ini dibendung dengan mengenakan kadar tabarru' yang tinggi supaya dapat mengurangkan kemudaratan yang ditanggung oleh dana tabarru'.

Tegasnya proses pengunderaitan yang diamalkan ini bertujuan menghindari daripada terjadinya kemudaratan kepada dana takaful jika tidak dilindungi dengan baik. Proses ini juga merupakan suatu pengurusan risiko di mana syarikat membuat penilaian terperinci sebelum menerima penyertaan individu ke dalam takaful.

\footnotetext{
38 Aḥmad bin Muḥammad al-Ẓarqā', Syarḥ al-Qawā 'id al-Fiqhiyyah (Damsyik: Dār al-Qalam, 1989), 219.

39 Aḥmad bin Muḥammad al-Ẓarqā’, Syarh al-Qawā 'id al-Fiqhiyyah, 179.

40 Abū Bakar Aḥmad bin Ḥusayn al-Bayhāqī, Ma'rifah al-Sunan wa Athār, Bab Ma 'rifah al-Sunan, no. Hadith 11979 (Qāhirah: Dār al-Wa'i, 1991).305.

${ }^{41}$ Aḥmad bin Muḥammad al-Zarāā', Syarh al-Qawā 'id al-Fiqhiyyah, 207.
} 
Dari satu perspektif, ia dilihat tidak adil apabila mengecualikan penyertaan peserta dalam takaful, tetapi realiti sesuatu perkara itu mestilah diketahui. Sesuatu perkara yang ideal jika ingin dilaksanakan, perlu dilihat pada realitinya terlebih dahulu iaitu takaful yang diamalkan pada hari ini adalah merupakan takaful yang diurus oleh syarikat yang terlibat dalam sektor perniagaan. Oleh itu, ia secara tidak langsung turut mengambil berat mengenai keuntungan dan kerugian syarikat. Takaful tidak menafikan sepenuhnya manfaat perlindungan kepada pemohon, akan tetapi takaful akan menetapkan keputusan sama ada untuk mengenakan bayaran lebih sekiranya pemohon berisiko tinggi. Sebagai contoh, syarikat takaful berhak membuat keputusan untuk mengklasifikasikan peserta dalam kelas atau kategori yang sesuai dengan pekerjaan pemohon. Manakala, pengecualian hanya diberikan sekiranya pekerjaan itu sangat merbahaya sehingga syarikat tidak mampu untuk memberi perlindungan kepada pemohon. Hal ini terjadi kerana syarikat perlu menjaga dana tabarru * supaya berada dalam keadaan baik.

Andai kata semua permohonan akan diterima dalam takaful tanpa melakukan proses pengunderaitan, ia seolah-olah menjadikan takaful sebagai institusi kebajikan sedangkan realiti sebenar institusi takaful merupakan entiti perniagaan yang berorientasikan keuntungan. Sekiranya semua peserta yang menyertai takaful membayar sumbangan yang sama, maka akan berlaku ketidakadilan dalam penggunaan dana. Contohnya seperti rajah di bawah:

Rajah 1: Gabungan Individu Berisiko Tinggi dan Berisiko Rendah.

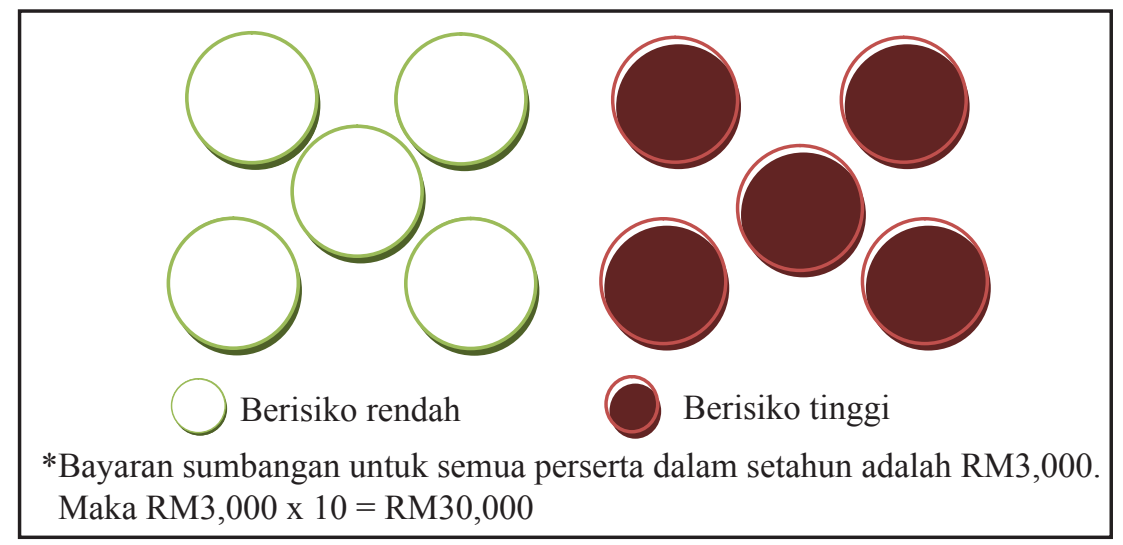

Sumber: Diubahsuai daripada gambaran kumpulan peserta takaful melalui temu bual dengan Penasihat Syariah. ${ }^{42}$

42 Wan Jemizan Wan Deraman (Ketua, Jabatan Pematuhan Syariah, Takaful Ikhlas Sdn. Bhd), dalam temu bual bersama beliau, 3 Mac 2014. 
Rajah 1 merupakan kumpulan individu yang menyertai takaful dengan mengambil pelan perlindungan yang sama dan membayar sumbangan yang sama. Andaikan kos perubatan untuk mereka yang berisiko tinggi adalah RM5,000 dan ke atas. Sedangkan mereka yang berisiko rendah tuntutan yang dilakukan adalah sekitar RM1,000 hingga RM3,000. Apabila mereka yang berisiko tinggi melakukan tuntutan, dana yang terkumpul akan berkurangan. Dengan baki dana yang ada, ia tidak mencukupi untuk menampung tuntutan yang bakal dilakukan oleh individu yang lain. Bayangkan individu yang berisiko tinggi membuat tuntutan sebanyak RM5,700, maka dana yang tinggal adalah RM24,300 (RM30,000-RM5,700). Kemudian, terdapat lagi beberapa individu berisiko tinggi yang lain membuat tuntutan sehingga mencecah RM19,7000, maka baki yang terdapat dalam dana adalah RM4,600 (RM24,300-RM19,700). Seterusnya jika ada lagi individu yang membuat tuntutan, dana yang ada tidak mencukupi untuk membayar tuntutan mereka.

Jadual 1: Contoh Perkiraan.

\begin{tabular}{cccc}
\hline Tarikh & Peserta & $\begin{array}{c}\text { Pengeluaran } \\
(\mathrm{RM})\end{array}$ & $\begin{array}{c}\text { Jumlah Dana } \\
\text { Tabarru' }\end{array}$ \\
& & & 30,000 \\
2/7/2013 & Perserta Berisiko Tinggi 1 & 5,700 & 24,300 \\
$3 / 7 / 2013$ & Perserta Berisiko Tinggi 2 & 6,500 & 17,800 \\
$5 / 7 / 2013$ & Perserta Berisiko Tinggi 3 & 8,000 & 9,800 \\
$7 / 7 / 2013$ & Perserta Berisiko Tinggi 4 & 5,200 & 4,600 \\
$10 / 7 / 2013$ & Peserta Berisiko Rendah 1 & 1,100 & 3,500 \\
$11 / 7 / 2013$ & Perserta Berisiko Tinggi 5 & 7,000 & $-3,500$ \\
$15 / 7 / 2013$ & Perserta Berisiko Rendah 2 & 1,800 & $-5,300$ \\
$20 / 7 / 2013$ & Perserta Berisiko Rendah 3 & 2,100 & $-7,400$ \\
$31 / 7 / 2013$ & Perserta Berisiko Rendah 4 & 2,600 & $-10,000$ \\
& Baki & & $-10,000$ \\
\hline
\end{tabular}

Sumber: Diubahsuai daripada gambaran gabungan peserta takaful melalui temu bual dengan Penasihat Syariah. ${ }^{43}$

Apabila individu itu berisiko tinggi, mereka lebih banyak melakukan tuntutan. Lalu, dana yang ada lebih banyak digunakan untuk mereka yang berisiko tinggi. Bagaimana pula untuk mereka yang berisiko rendah? Kemungkinan dana yang terkumpul tidak mencukupi untuk membantu individu yang berisiko rendah apabila mereka membuat tuntutan kerana umumnya seseorang yang mempunyai pelbagai penyakit kritikal, mereka akan terlebih

43 Wan Jemizan Wan Deraman (Ketua, Jabatan Pematuhan Syariah, Takaful Ikhlas Sdn. Bhd), dalam temu bual bersama beliau, 3 Mac 2014. 
dahulu ditimpa musibah berbanding mereka yang tiada penyakit. Dalam kes ini, elemen tolong-menolong hanya berpihak kepada mereka yang berisiko tinggi. Mereka yang berisiko rendah menolong mereka yang berisiko tinggi, tetapi mereka yang berisiko tinggi tidak mampu menolong mereka yang berisiko rendah. Sedangkan mereka sama-sama memerlukan dana tersebut untuk keperluan masing-masing. Oleh sebab itu, mereka perlu dikelaskan mengikut risiko yang dibawa.

Pengurusan risiko secara umumnya pula adalah diharuskan dan dituntut oleh Syarak. Ini bertepatan pula dengan konsep mașlahah dan Maqāṣid al-Syarī'ah yang memberi penekanan terhadap penjagaan harta. Ini semua membuktikan bahawa Syariat Islam yang diutuskan kepada umat manusia adalah bertujuan untuk menghasilkan kebaikan dan menolak kemudaratan. Hasil kajian mendapati, amalan pengunderaitan yang dipraktikkan di dalam institusi Takaful rata-ratanya memenuhi syariat tersebut. Faktor-faktor pengunderaitan yang diamalkan juga termasuk di bawah mașlahah mursalah iaitu tiada dalil khusus mengenainya sama ada menerima atau menolak mașlahah tersebut tetapi secara tersirat ia dimaksudkan oleh Syarak untuk dipelihara. ${ }^{44}$

Bagi mengelak daripada berlakunya anti-pemilihan, proses pengunderaitan ini perlu dilakukan kerana ia akan melibatkan bilangan tuntutan yang tinggi dan menyebabkan kedudukan kewangan syarikat terjejas ${ }^{45}$ dan dalam konteks takaful ia akan menjejaskan kelangsungan dana tabarru:

Pendekatan ini juga dilihat bermatlamat untuk menjaga mașlahah terhadap peserta takaful yakni dalam memastikan sumbangan tabarru' yang dikenakan ke atas seseorang pemohon, dikira sejajar dengan penilaian risiko yang dibawanya. Ini dapat mengelakkan daripada berlakunya kekurangan dana syarikat disebabkan oleh faktor anti-pemilihan ini. Sekiranya dana tabarru ‘ berkurangan dan tidak mencukupi, pengendali takaful akan meminjam daripada pemegang saham. Pinjaman tersebut berdasarkan kontrak qard iaitu pinjaman yang mana tidak dikenakan sebarang bayaran tambahan.

Perlu difahami bahawa penyertaan individu dalam takaful seharusnya ketika individu dalam keadaan sihat. Takaful bukan ditubuhkan untuk mereka yang berpenyakit. Bayangkan jika takaful banyak menerima individu yang berpenyakit sahaja, maka apa yang akan berlaku pada mereka yang kurang berisiko? Dan bagaimana pula keadaan pemegang saham serta dana syarikat? Jika individu menyertai takaful ketika dalam keadaan sihat, ia

\footnotetext{
44 'Abd al-Karīm Zaydān, al-Wajīz fì Ușūl al-Fiqh (Beirūt: Muassasah al-Risālah, 1996), 237.

45 Hendon Redzuan et al., Prinsip Pengurusan Risiko, 59.
} 
akan memudahkan syarikat takaful dalam melakukan penerimaan mengikut apa yang diinginkan oleh peserta. Walaupun begitu, takaful mungkin boleh mewujudkan satu dana khusus untuk mereka yang mempunyai penyakit kritikal. Dana tersebut hanya digunakan jika mereka membuat tuntutan bagi penyakit-penyakit tertentu. Mungkin takaful boleh meletakkan syarat kepada mereka hanya membenarkan membuat tuntutan setahun sekali. Ianya bagi mengurangkan kekerapan dalam melakukan tuntutan. Dengan adanya dana tersebut, walaupun ia mungkin tidak dapat membayar membayar sepenuhnya perbelanjaan rawatan mereka, sekurang-kurangnya, ia boleh meringankan beban mereka dalam membayar rawatan yang tinggi kosnya. Alternatif lain bagi pengumpulan dana bagi membantu individu yang berisiko tinggi ini adalah dengan mendapat sumbangan daripada baitulmal. Baitulmal boleh memperuntukkan sejumlah dana tertentu untuk membantu golongan yang berisiko tinggi dan diuruskan oleh syarikat takaful sebagai dana tambahan bagi para peserta dalam kategori berisiko tinggi. Ini bermakna peserta diterima dengan bayaran yang lebih tinggi ditambah dengan dana sumbangan baitulmal untuk dana tabarru ' bagi peserta kategori ini. Jika institusi-institusi ini dapat bergerak seiring dalam masyarakat, maka ia dapat membantu dalam mencapai Maqāșid al-Syarī'ah dalam menjaga nyawa, agama dan lain-lain.

Keputusan pengunderait untuk mengenakan kadar tabarru' yang tinggi kepada pemohon yang berisiko tinggi pula menunjukkan elemen keadilan cuba diterapkan dalam penilaian yang dilakukan terhadap pemohon. Firman Allah SWT:

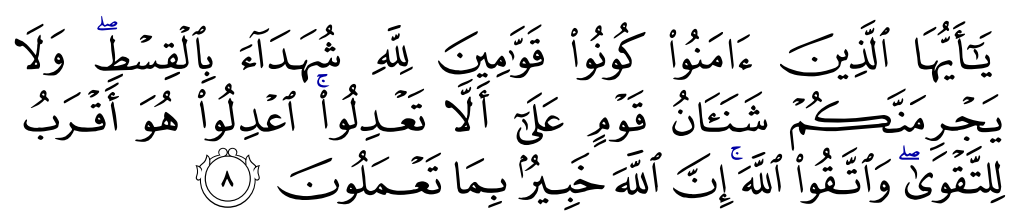

"Wahai orang-orang yang beriman! Hendaklah kamu semua sentiasa menjadi orang-orang yang menegakkan keadilan kerana Allah, lagi menerangkan kebenaran; dan jangan sekalikali kebencian kamu terhadap sesuatu kaum itu mendorong kamu kepada tidak melakukan keadilan. Hendaklah kamu berlaku adil (kepada sesiapa jua) kerana sikap adil itu lebih hampir kepada taqwa. Dan bertaqwalah kepada Allah, sesungguhnya Allah Maha Mengetahui dengan mendalam akan apa yang kamu lakukan."

(Surah al-Mā'idah, 5: 8)

Dalam ayat di atas Allah SWT memerintahkan hambaNya untuk berlaku adil sesama manusia kerana adil itu menghampiri taqwa. Ini jelas membuktikan 
Islam meletakkan keadilan pada kedudukan yang tinggi dalam sistem perundangannya. Konsep keadilan ini juga turut diaplikasikan dalam industri takaful khususnya di dalam proses pengunderaitan yang mengenakan bayaran tabarru 'yang tinggi sesuai dengan risiko dan keadaan pemohon.

Unsur keadilan juga turut diterapkan dalam pengambilan setiap faktorfaktor pengunderaitan. Dengan adanya proses tersebut, pengunderait akan mengelaskan individu mengikut tahap risiko masing-masing serta akan menentukan kadar sumbangan tabarru' yang berbeza mengikut keadaan individu. Ini kerana bayaran yang tinggi akan dikenakan kepada mereka yang berisiko tinggi begitu juga sebaliknya. Ini menunjukkan elemen keadilan yang ada dalam takaful. Bayaran sumbangan yang tinggi dikenakan kerana risiko yang akan ditanggung adalah tinggi.

Pemilihan individu yang ingin menyertai takaful meliputi prosedur menilai maklumat dan laporan kesihatan untuk menentukan sama ada pemohonan yang dilakukan oleh pemohon diklasifikasikan sebagai standard, sub-standard atau decline. Kemudian, pengunderait akan menentukan kadar tabarru' yang perlu disumbangkan oleh pemohon. Kadar tabarru' ini ditentukan sesuai dengan risiko individu berdasarkan kepada penilaian yang telah dilakukan terhadap diri pemohon.

Faktor-faktor seperti umur, jantina, kehidupan peribadi, pekerjaan, latarbelakang keluarga, hobi, dan tahap kesihatan turut diambil kira dalam proses pengunderaitan khususnya dalam produk takaful keluarga. Setiap faktor ini akan dinilai berdasarkan manual pengunderaitan yang ada di setiap syarikat takaful. Faktor-faktor ini akan dinilai dengan teliti bagi memastikan kadar tabarru' dikenakan bersesuaian dengan risiko yang ada pada pemohon.

\section{KESIMPULAN}

Proses pengunderaitan yang diamalkan oleh industri insurans dan takaful adalah berdasarkan konsep yang sama. Kedua-duanya turut mengambilkira faktor-faktor pengunderaitan dalam menilai risiko pemohon. Walaupun terdapat kajian barat yang berpandangan bahawa wujudnya isu ketidak adilan dalam penggunaan faktor-faktor tersebut, tetapi secara praktikalnya konsep pengunderitan yang dilaksanakan di dalam industri takaful dilihat sebagai sesuatu yang tidak bercanggah dengan prinsip Syariah. Ini kerana tiada dalil khusus yang mengharamkan penggunaan faktor-faktor pengunderaitan dalam menilai risiko pemohon yang ingin menyertai takaful.

Syarikat takaful yang bertindak sebagai pemegang amanah kepada dana sumbangan peserta pula akan sentiasa melindungi dana tabarru untuk 
memastikan ianya disalurkan pada jalan yang betul. Oleh kerana itu, faktorfaktor pengunderaitan telah digunakan untuk menilai risiko yang dibawa oleh pemohon. Proses pengunderaitan ini juga penting untuk mengelak daripada berlakunya kemudaratan kepada dana tabarru'ini sesuai dengan tanggungjawab syarikat takaful untuk menjaga kepentingan setiap pihak sama ada pemegang saham ataupun juga para pesertanya.

Islam melihat risiko sebagai lumrah perniagaan dan turut menganjurkan bahawa risiko perniagaan ini mampu diminimumkan sekiranya diurus dengan baik. Proses pengunderaitan juga dilihat sebagai satu cabang pengurusan risiko dalam industri takaful. Justeru, bagi mengelakkan syarikat daripada menanggung risiko yang lebih besar, mendorong mereka untuk memilih hanya permohonan daripada individu yang tidak mendatangkan kemudaratan terhadap dana tabarru'. Risiko-risiko tersebut dilihat akan mendatangkan kemudaratan atau kerugian yang besar kepada syarikat dan sudah pastinya akan menjejaskan perjalanan syarikat terutamanya bilamana ianya menjejaskan dana risiko yang digunakan untuk melindungi perserta yang ditimpa musibah.

Secara ringkasnya dapat disimpulkan bahawa proses pengunderaitan yang diamalkan dalam takaful tidaklah bercanggah dengan dengan prinsip Syariah. Ini kerana, terdapat risiko yang perlu ditanggung oleh syarikat untuk memastikan agar dana syarikat dan dana tabarru' sentiasa berada dalam keadaan yang baik. Risiko perniagaan ini pula dapat diminimumkan sekiranya langkah stategik diambil. Antara langkah strategik yang boleh diambil untuk mengurangkan risiko kekurangan dana syarikat adalah dengan membuat penilaian ke atas setiap permohonan melalui proses pengunderaitan dengan mengambil kira setiap faktor-faktor pengunderaitan yang telah ditetapkan.

Bagi peserta yang berisiko tinggi, alternatif perlu dicari untuk membolehkan mereka turut serta menyertai takaful. Penyertaan tersebut memerlukan penyertaan masyarakat secara menyeluruh dengan cara mewujudkan hubungan di antara syarikat takaful dan baitulmal. Satu perkara yang dilihat diluar dari kerangka perniagaan takaful yang diamalkan sekarang namun boleh dilaksankan jika semangat dan konsep takaful cuba diterapkan secara menyeluruh.

\section{PENGHARGAAN}

Pengkaji mengucapkan setinggi-tinggi penghargaan kepada Universiti Malaya kerana membiayai penyelidikan RG378-12HNE. 


\section{RUJUKAN}

'Abd al-Karīm Zaydān, al-Wajīz fì Uṣūl al-Fiqh (Beirūt: Muassasah alRisālah, 1996).

Ahmad Mazlan Zulkifli et al., Asas Amalan Takaful: Pengunderaitan Takaful Perubatan dan Kesihatan (Kuala Lumpur: IBFIM, 2012).

Aḥmad bin Muḥammad al-Zarqā', Syarh al-Qawā 'id al-Fiqhiyyah (Damsyik: Dār al-Qalam, 1989).

Basri Ibrahim, Urusan Kewangan Semasa Menurut Perspektif Islam (Kuala Lumpur: al-Hidayah, 2005).

Bernard L. Webb, Connor M. Harrison \& James J. Markham, Insurance Operation, $2^{\text {nd }}$ ed. (Malvern: American Institute for Chartered Property Casualty Underwriter, 1997).

Daniel E. Palmer, 'Risk Assesment and Fairness: An Ethical Analysis,' in Insurance Ethics for a More Ethical World (Elsevier Ltd., 2007).

Eric A. Wiening et al., Personal Insurance (America: American Institute for Chartered Property Casualty Underwriters/Insurance Institute of America, 2002).

Hendon Redzuan et al., Prinsip Pengurusan Risiko dan Insurans (Petaling Jaya: Person Malaysia Sdn. Bhd., 2006).

Htay et al., 'Shariah Scholars' Viewpoint on the Practice of Underwriting and Rating for Individual Participants in Family Takaful,' (International Islamic Banking, Finance and Investment Conference, 19-20 December 2011).

INCIEF, Takaful: Reality and Challenge (Petaling Jaya: Pearson Malaysia Sdn. Bhd., 2012).

Jalāl al-Dīn 'Abd al-Rahmān al-Ṣuyūți, al-Ashbah wa al-Naẓā'ir fì Qawā 'id wa Furu' Fiqh al-Syāfi 'iyah (Beirūt: Dār al-Kutub al-'Ilmiyyah, 2007).

James L. Athearn, Risk and Insurans (New York: West Publishing Co., 1997).

Joseph Heath, 'Reasonable Restrictions on Underwriting,' Research in Ethical Issues in Organizations, vol. 7 (2007).

Mohd Fauzi Abu \& Kamaruzaman Nordin, 'Perkembangan dan Prospek Industri Takaful Global,' dalam Sistem Takaful di Malaysia Isu-isu Kontemporari, ed. Asmak Ab. Rahman et al. (Kuala Lumpur: Universiti Malaya, 2008).

Muḥammad bin Yazid al-Qazwīn̄i, Sunan Ibn Majah (Arab Saudi: Dār Ihyā̄' al-Kutub al-'Arabiyyah, t.t.). 
Muhammad 'Uthmān Shubāyr, al-Mu'āmalāt al-Māliyyah al-Mu'āṣirah (Oman: Dār al-Nafā'is, 2007).

Norman Daniels, 'Insurability and the HIV Epidemic: Ethical Issues in Underwriting,' JSTOR, 68/4 (1990).

Patrick L. Brockett, 'The Genetics Revolution, Economics, Ethics and Insurance,' Journal of Business Ethic, 16 (1997).

Roslinah Daud, 'Underwriting Family Schemes,' ICMIF Takaful (2009). Lihat http://www.takaful.coop/index.php?option=com_content\&view=article \&id=73\&Itemid=145., diakses pada 10 Mei 2014 .

Tobias Frenz et al., Takaful and Retakaful: Advanced Principles \& Practice (Kuala Lumpur: IBFIM, 2010).

Vaughan E. J \& Vaughan T. M, Essential of Insurance: A Risk Management Perspective (USA: John Wiley \& Sons, INC., 1995).

Vaughan E. J \& Vaughan T. M, Risk Management (New York: John Wiley \& Son, Inc., 1997).

Wouter P. J., 'Insurance Risk Classification in The EC: Regulatory Outbook,' Oxford Journal of Legal Studies 14 (1994).

Yūsuf al-Qaraḍāwī, F̄̄ Fiqh Awlāwiyyat: Dirāsat Jadīdah Daw'al-Qur'ān wā al-Sunnah (Qāhirah: Maktabah Wahbah, 1999).

\section{Temu bual}

Wan Jemizan Wan Deraman (Ketua, Jabatan Pematuhan Syariah, Takaful Ikhlas Sdn. Bhd), dalam temu bual bersama beliau, pada 3 Mac 2014. 